\title{
COVID-19: Reflections from Policy to Implementation
}

\author{
Sakhawat Ali Randhawa
}

COVID-19 pandemic has paralyzed every section of society around the world. Inside our public health bubble, people may think we have conquered it, but the war is not over yet. The overall health of our society, our country is affected by our efforts and the health of the world population is another area where we can influence and improve the overall quality of life of the whole world.

Policy makers need data for making informed decisions. The government data of Pakistan is always questionable for many reasons in every field. Real numbers are our work report card so policy makers need to understand real data value. The lack of real data in making any decision is bad but it is a problem of life and death in the epidemic or pandemic like this we are facing. Data itself can not lie but for some reason, data collectors can. It is essential to have reliable numbers; otherwise strategies that develop in the dark will fail even with the good intentions. ${ }^{1}$ Epidemiologists have to draw conclusions from incomplete data. People have been tested and positives numbers are there but not surveillance data. Knowing the level of cases in a geographical area is a key element in an outbreak control strategy. The spread of COVID-19 in Pakistan was expected to reach its maximum these days, but we need to be more careful on how to get the actual numbers and reliable data.

The analysis of low mortality and morbidity compared to the West may be based on the age distribution and other factors of our country. ${ }^{2}$ It is important to avoid spikes coming on Eid al-Adha, but it is also important to keep focus on future spikes. We must know the clustering of cases. This is the first important step in controlling the spread of the disease. In our Rahim Yar Khan district we have a strategy of detection and active contact tracing to control this spread. For effective public health monitoring, the district Rahim Yar Khan is divided into 27 zones. ${ }^{3}$ Each zone has the geographical boundaries of the police station. Each zone consists of a team consisting of a physician, paramedic, police officer, revenue officer and other law enforcement agencies. When needed, the number of teams in a zone increased as the workload increased in urban areas and so did the number of teams.

Contact tracing is essentially an art of communication which gets the trust of patients and their families. An effective system for contact tracing includes a valid epidemiological information of cases. Detection of more connections of cases shall help in controlling its transmission. Once we start identifying case contact, we can identify asymptomatic cases and create a barrier on active transmissions.

Public health officials must first share the news, be honest and transparent. Stake holders including community and media participation is of paramount importance to pandemic control strategies. Choosing the right person for the right job is very important and especially in the epidemic it is a difference between life and death. We can't win a public health war with an operation room filled with people who have no experience about public health. To deal with COVID-19 you need people who are skilled in fighting battles against bacteria and viruses. Public health professionals do not treat the sick; instead they advise policy makers, oversee the trajectory of the epidemic, and ensure hospital readiness. We are seeing a dearth of skilled persons because the very people whose skills are sorely needed to handle the pandemic are on the verge of burning out. The public health sector requires specialized training and skills.

Healthcare workers are doing great job and feel duty-bound to be helping their countrymen during this unprecedented pandemic. The people who are on the front line and doing their duty have had to recalibrate their lives. They have worked relentlessly. The cost was worth it when we still are looking to create an opportunity of controlling COVID-19. 
But they're also very tired and de motivated by the government's failure to give them announced extra basic salary. Even after four months of announcement, this promise is not fulfilled. The pandemic may once again intensify and so will their frustration and fatigue. The number of epidemiologists is low in country and those who specialize in pandemic-level infectious threats is even small. ${ }^{4}$ Public health experts are demoralized as their voice which is based on evidence is politically ignored. District Health Authority is using its all resources to implement a well coordinated plan to strengthen district's ability to test, trace and treat the infected people.

The pandemic is also bringing out academia's darker sides too, which includes unhealthy financial lust, and competition. Public health successes come slowly but very cost effective, based on the sustained efforts of variety of people, with different skills. Millions of people are alive and healthy due to some simple but effective public health initiatives. A major part of public health impact lies in preventive level of care. It means that we will be able to work on plans that aim to actually prevent the illnesses and of course that impact so many people's health. Identifying the most effective evidence based interventions and translating the research into policy and practice is crucial to reaching the goal of a healthier nation.

\author{
Dr. Sakhawat Ali Randhawa \\ MBBS; MCPS-HCSM; FELTP \\ Chief Executive Officer, \\ District Health Authority, Rahim Yar Khan. \\ Government of the Punjab, Pakistan. \\ Email:drrandhawa7@gmail.com
}

\title{
REFERENCES
}

1. Centers for Disease Control and Prevention. Available from: https://www.cdc.gov/surveillance/ Accessed on 25th July, 2020

2. World Health Organization. Available from: https://covid19.who.int/region/emro/country/pk Accessed on 25th July, 2020

3. Health Information \& Service Delivery Unit(HISDU). Primary \& Secondary Healthcare Department (P\&SHD), Govt. of The Punjab. Available from: http://covid19.pshealthpunjab.gov.pk/ ContactTracked/DistrictWise. Accessed on 25th July, 2020

4. Centers for Disease Control and Prevention. Available from: https://www.cdc.gov/coronavirus/2019ncov/covid-data/faq-surveillance.html. Accessed on 25th July, 2020 